\title{
Graphene-reinforced metal-organic frameworks derived cobalt sulfide/carbon nanocomposites as efficient multifunctional electrocatalysts
}

\author{
Laicong Deng ${ }^{1}$, Zhuxian Yang ${ }^{1}$, Rong $\mathrm{Li}^{2}$, Binling Chen ${ }^{1}$, Quanli Jia ${ }^{3}$, Yanqiu Zhu ${ }^{1}$, Yongde Xia (ه) ${ }^{1}$ \\ 1 College of Engineering, Mathematics and Physical Sciences, University of Exeter, Exeter EX4 4QF, UK \\ 2 Chemical Synthesis and Pollution Control Key Laboratory of Sichuan Province, College of Chemistry and Chemical Engineering, China West \\ Normal University, Nanchong 637000, China \\ 3 Henan Key Laboratory of High Temperature Functional Ceramics, Zhengzhou University, Zhengzhou 450052, China
}

(C) The Author(s) 2021. This article is published with open access at link.springer.com and journal.hep.com.cn

\begin{abstract}
Developing cost-effective electrocatalysts for oxygen reduction reaction (ORR), oxygen evolution reaction (OER) and hydrogen evolution reaction (HER) is vital in energy conversion and storage applications. Herein, we report a simple method for the synthesis of graphene-reinforced $\mathrm{CoS} / \mathrm{C}$ nanocomposites and the evaluation of their electrocatalytic performance for typical electrocatalytic reactions. Nanocomposites of $\mathrm{CoS}$ embedded in $\mathrm{N}, \mathrm{S}$ co-doped porous carbon and graphene (CoS@C/Graphene) were generated via simultaneous sulfurization and carbonization of one-pot synthesized graphite oxide-ZIF-67 precursors. The obtained CoS@C/ Graphene nanocomposites were characterized by X-ray diffraction, Raman spectroscopy, thermogravimetric analysis-mass spectroscopy, scanning electronic microscopy, transmission electronic microscopy, X-ray photoelectron spectroscopy and gas sorption. It is found that $\mathrm{CoS}$ nanoparticles homogenously dispersed in the in situ formed $\mathrm{N}, \mathrm{S}$ co-doped porous carbon/graphene matrix. The CoS@C/10Graphene composite not only shows excellent electrocatalytic activity toward ORR with high onset potential of $0.89 \mathrm{~V}$, four-electron pathway and superior durability of maintaining 98\% of current after continuously running for around $5 \mathrm{~h}$, but also exhibits good performance for OER and HER, due to the improved electrical conductivity, increased catalytic active sites and connectivity between the electrocatalytic active $\operatorname{CoS}$ and the carbon matrix. This work offers a new approach for the development of novel multifunctional nanocomposites for the next generation of energy conversion and storage applications.
\end{abstract}

Received April 14, 2021; accepted June 14, 2021

E-mail: Y.Xia@exeter.ac.uk
Keywords MOF derivative, graphene, electrocatalyst, oxygen reduction reaction, oxygen evolution reaction, hydrogen evolution reaction

\section{Introduction}

The increasing energy demand together with the potential depletion of fossil fuel-based energy sources has triggered worldwide intense research on renewable energy conversion and storage systems that are highly efficient, low cost and environmentally friendly [1,2]. In a variety of renewable energy related technologies, including fuel cells, metal-air batteries and water splitting [3], efficient catalysts toward electrochemical oxygen reduction reaction (ORR), oxygen evolution reaction (OER) [4] and hydrogen evolution reaction (HER) play paramount roles [4-7]. On one hand, ORR is currently the ubiquitous cathode reaction in fuel cells, and Pt or its alloys are the most active electrocatalysts for ORR [8-10]; on the other hand, OER and HER lie at the heart of the electrochemical water splitting and metal-air batteries, and $\mathrm{Ru}$ oxides and $\mathrm{Pt}$ are the benchmark electrocatalysts for OER and HER, respectively [11-13]. However, both Pt or its alloys and $\mathrm{Ru}$ oxides are among the rarest elements on earth and expensive, which inevitably hinder their large-scale applications. As a result, it is highly desirable to develop efficient and non-noble metal based electrocatalysts with multifunctional catalytic activities toward ORR, OER and HER simultaneously, which is sought after for renewable energy applications in full water splitting to generate emission-free $\mathrm{H}_{2}$ as well as $\mathrm{O}_{2}$ [14-18].

Recently, Co based materials including metallic Co, $\mathrm{CoO}$ and $\mathrm{CoS}$ combined with N, S, P heteroatom doped/ co-doped carbon materials have demonstrated promising 
multifunctional electrocatalytic activities in ORR/OER or OER/HER or ORR/OER/HER [3,4,15,16,18-24]. Therefore, numerous synthesis approaches have been developed to generate Carbon-based electrocatalysts with active Co components $[25,26]$. Among the diverse synthesis strategies, the use of metal-organic frameworks (MOFs) as precursors is a facile and effective route to produce high performance carbon-based electrocatalysts, due to the controllable crystalline structures the adjustable compositions as well as the tunable porous sizes and surface areas of MOFs [27-31]. As a sub-family of MOFs, zeolitic imidazolate frameworks (ZIFs) have been widely studied in gas storage, separation, catalysis and drug delivery [3234]. Due to the rich $N$ content in the organic linkers of ZIFs, carbonization of ZIFs can readily lead to the formation of metal components uniformly dispersed in $N$-doped porous carbon materials [35,36]. In our previous work, we successfully produced nanocomposites of CoS homogeneously dispersed in N, S co-doped porous carbon by a facile one-step simultaneous sulfurization and carbonization of ZIF-67 [37]. Due to their unique coreshell structure, high porosity, homogeneous dispersion of active $\mathrm{CoS}$ component together with $\mathrm{N}$ and $\mathrm{S}$ co-doped porous carbon, the resulting nanocomposites exhibit excellent ORR and OER performance with superior durability $[22,37,38]$.

Moreover, in the past years graphene-based materials were widely explored as catalyst support due to their high surface area, good chemical stability, excellent electrical conductivity, as well as strong adhesion to catalyst particles [39-41]. In particular, heteroatoms doped graphene not only exhibits improved electron mobility, but also shows efficiently introduced chemical active sites for catalytic reactions and provides increased anchoring sites for catalytical nanoparticle deposition [3,42-44]. However, it still remains a challenge to effectively support catalytically active species on graphene with uniform distribution so as to improve the performance of the electrocatalyst. In this regard, a composite of ZIF derivative and graphene may potentially be promising electrocatalyst with good charge mobility, high surface area and highly dispersed active species for relevant electrocatalytic reactions.

In this work, we developed a simple approach to prepare graphene-reinforced $\mathrm{CoS}$ embedded in heteroatoms doped porous carbon via a simultaneous sulfurization and carbonization of one-pot synthesized graphite oxide/ZIF67 composite (GO-ZIF-67). ZIF-67 is rich in $\mathrm{Co}-\mathrm{N}$ moieties and is an excellent precursor for the preparation of $\mathrm{CoS}$ on carbon. GO is in situ introduced during the synthesis of ZIF-67 precursor and can be readily reduced to graphene during the high temperature heat process. Consequently, heat treatment of the in situ synthesized GO-ZIFs in $\mathrm{H}_{2} \mathrm{~S}$ atmosphere at high temperature can result in $\mathrm{CoS}$ dispersed in $\mathrm{N}, \mathrm{S}$ co-doped porous carbon and graphene with improved catalytic active sites and electrical conductivity. Various techniques, including X-ray diffraction (XRD), transmission electron microscopy (TEM), scanning electron microscopy (SEM), $\mathrm{N}_{2}$ adsorption, thermogravimetric analysis-mass spectrometer (TGAMS), X-ray photoelectron spectroscopy (XPS) and Raman spectroscopy were used to investigate the physicochemical properties of the obtained composites and their performance in relevant electrocatalytic reactions were evaluated. Compared to the graphene-free sample, the resulting graphene-reinforced $\mathrm{CoS} / \mathrm{C}$ nanocomposites exhibit multifunctional electrocatalytic performance for ORR, OER and HER with improved activities and good durabilities, due to the increased electrical conductivity, catalytic active sites and connectivity between $\operatorname{CoS}$ and carbon/graphene.

\section{Experimental}

\subsection{Synthesis of GO-ZIF67 precursors}

GO was prepared via a slightly modified Hummers method [45], then the GO-ZIF composites were synthesized through an established approach [46]. Briefly, 2-methylimidazole (Hmim) was dissolved in deionized water, followed by adding calculated amount of GO under stirring. Then, $\mathrm{Co}\left(\mathrm{NO}_{3}\right)_{2} \cdot 6 \mathrm{H}_{2} \mathrm{O}$ was dissolved in deionized water and the two solutions were mixed together under further stirring at room temperature for $8 \mathrm{~h}$. The molar ratio of the mixture is $\mathrm{Co}^{2+}: \mathrm{Hmim}: \mathrm{H}_{2} \mathrm{O}=$ 1:58:1100. The purple product was collected by filtration followed by washing with deionized water and then airdried at room temperature for $48 \mathrm{~h}$. The samples were denoted as $x$ GO-ZIF67, where $x(x=5,10,20$ wt- $\%)$ stands for the weight percentage of GO in the composites. For comparison, a pristine ZIF-67 precursor was also synthesized following the same procedure without the addition of GO.

\subsection{Synthesis of $\mathrm{CoS} @ \mathrm{C} /$ Graphene composites}

The air-dried GO-ZIF67 and pure ZIF-67 precursors were sulfurized in $\mathrm{H}_{2} \mathrm{~S}$ atmosphere. Typically, $0.25 \mathrm{~g}$ dried $x$ GO-ZIF67 composite was loaded into an alumina boat and placed in the center of a tube furnace, followed by heating the furnace to $800{ }^{\circ} \mathrm{C}$ with a ramp rate of $10^{\circ} \mathrm{C} \cdot \mathrm{min}^{-1}$ under Ar flow of $50 \mathrm{~mL} \cdot \mathrm{min}^{-1}$. At $800{ }^{\circ} \mathrm{C}$, $\mathrm{H}_{2} \mathrm{~S}$ gas was charged into the furnace at a flow rate of $20 \mathrm{~mL} \cdot \mathrm{min}^{-1}$ in addition to the Ar flow for $1 \mathrm{~h}$, then the $\mathrm{H}_{2} \mathrm{~S}$ gas flow was stopped and the furnace was switched off to cool down to room temperature under Ar flow only. The resulting composites were labeled as CoS@C/xGraphene. The product obtained from ZIF-67 precursor was named as CoS@C. 


\subsection{Materials characterizations}

XRD patterns were recorded with $\mathrm{Cu} \mathrm{K} \alpha$ radiation $(40 \mathrm{kV}$ $40 \mathrm{~mA}$ ) at a step size of $0.02^{\circ}$ and $1 \mathrm{~s}$ per step. TGA was performed on a TA SDT Q600 from room temperature to $800{ }^{\circ} \mathrm{C}$ with a ramp rate of $10{ }^{\circ} \mathrm{C} \cdot \mathrm{min}^{-1}$ in air with a flow rate of $100 \mathrm{~mL} \cdot \mathrm{min}^{-1}$. A Hiden QGA MS was coupled with the Q600 instrument to monitor the gaseous compositions of the exhaust emission. SEM images were recorded using a Philips XL-30 in a high vacuum mode at an acceleration voltage of $20 \mathrm{kV}$. Before the measurement, all samples were coated with gold to reduce the effects of charging. TEM images were recorded by a JOEL 2100 at an acceleration voltage of $100 \mathrm{kV}$. Raman spectra were obtained using a Renishaw in Via Raman microscope with the excitation laser beam at a wavelength of $532 \mathrm{~nm} . \mathrm{N}_{2}$ adsorption measurements were carried out on a Quantachrome Autosorb-iQ gas sorptometer via conventional static volumetric technique. Before testing, the samples were dried overnight at $110{ }^{\circ} \mathrm{C}$ and evacuated for $4 \mathrm{~h}$ at $200{ }^{\circ} \mathrm{C}$ under vacuum. Then, $\mathrm{N}_{2}$ sorptions were measured at $-196{ }^{\circ} \mathrm{C}$. Brunauer-Emmett-Teller method was used to calculate the surface area of the samples, based on the adsorption data in the partial pressure $\left(P / P_{0}\right)$ range of 0.02 0.22 . The total pore volume was determined from the amount of adsorbed $\mathrm{N}_{2}$ at $P / P_{0}$ ca. 0.99. XPS was performed on a Kratos Axis Ultra system with a monochromated $\mathrm{Al} \mathrm{Kr}$ X-ray source operated at $10 \mathrm{~mA}$ emission current and $15 \mathrm{kV}$ anode potential.

\subsection{Electrocatalytic measurements}

Electrocatalytic performance of the catalysts was evaluated by cyclic voltammograms (CV), linear sweep voltammograms (LSV) and chronoamperometry in a three-electrode electrochemical cell which was connected to a computercontrolled potentiostat (CHI 760D), coupled with a rotating disk electrode (RDE) system. A platinum wire and an $\mathrm{Ag} / \mathrm{AgCl}$ electrode were used as the counter electrode and the reference electrode respectively. A bare glassy carbon electrode (GCE) of $3 \mathrm{~mm}$ in diameter or modified GCE with the studied material was used as the working electrode. The electrode was polished on a chamois leather with drops of $0.05 \mu \mathrm{m}$ alumina for 15 min to obtain a mirror-like surface. The modified GCE was prepared by casting a $5 \mu \mathrm{L}$ of the catalyst ink, which was obtained by ultrasonically dispersing $1 \mathrm{mg}$ of the catalyst in $0.5 \mathrm{~mL}$ alcohol with $5 \mu \mathrm{L} 0.05$ wt-\% nafion, onto the fresh surface of the pre-treated GCE electrode and dried in air to form a uniform thin film. Through this method, the loading amount of each catalyst was kept to be $141.5 \mu \mathrm{g} \cdot \mathrm{cm}^{-2}$. For ORR and OER, the measurements were carried out at room temperature in $0.1 \mathrm{~mol} \cdot \mathrm{L}^{-1} \mathrm{KOH}$ solution, which was purged with high purity nitrogen or oxygen at a flow rate of $20 \mathrm{~mL} \cdot \mathrm{min}^{-1}$ for at least $30 \mathrm{~min}$ prior to each measurement. For HER, the tests were carried out at room temperature in $0.5 \mathrm{~mol} \cdot \mathrm{L}^{-1} \mathrm{H}_{2} \mathrm{SO}_{4}$ solution. The electrode potential reported in this paper is relative to the reversible hydrogen electrode (RHE) potential.

\section{Results and discussion}

The in situ synthesized GO-ZIF67 precursors, pristine ZIF67 and GO are characterized and presented in Fig. S1 (cf. Electronic Supplementary Material, ESM). As shown in Fig. S1(a), the XRD of GO displays a characteristic strong peak at $2 \theta$ of $10.5^{\circ}$, which is corresponding to the average interlayer spacing of $8.4 \AA$. The XRD patterns of the pristine ZIF-67 suggest the formation of pure sodalite-type crystal structures. The in situ synthesized GO-ZIF67 composites show similar XRD patterns to that of the pristine ZIF-67, which indicates the introduction of GO into the synthesis gel does not affect the crystalline structure of ZIF-67. No XRD peak from GO can be observed, which could be due to the overlapping of the XRD peaks of GO and ZIF-67. In addition, the amount of GO has no observable effect on the XRD patterns of the GO/ZIF-67 composites. However, as shown in Fig. S1(b), the introduction of GO into the synthesis gel of ZIF-67 can obviously affect the $\mathrm{N}_{2}$ sorption capacities and consequently influence the textural properties of the resulting GO-ZIF67 composites. The representative TEM image (Fig. S1(c)) of the as-synthesized GO-ZIF67 exhibits the typical rhombic dodecahedron crystals with particle size up to $160 \mathrm{~nm}$ and observable micropores.

The one-pot synthesized GO-ZIF67 and pristine ZIF-67 were used as precursors to realize one-step simultaneous sulfurization and carbonization by heat treatment in $\mathrm{H}_{2} \mathrm{~S}$ atmosphere to produce composites CoS@C/10Graphene and $\operatorname{CoS} @ \mathrm{C}$ respectively, and these samples were fully characterized and presented in Figs. 1-3. The XRD results of these composites are presented in Fig. 1(a). As expected, both composites exhibit XRD patterns completely different from their precursors, which can be indexed to $\mathrm{Co}_{1-x} \mathrm{~S}$ (ICDD PDF\# 42-0826) with the hexagonal structure in P63/mmc space group (No. 194) [37], which is consistent with previously reported results [37]. Moreover, sample CoS@C/10Graphene displays sharper XRD peaks with higher intensity than that of $\mathrm{CoS} @ \mathrm{C}$, indicating improved crystallinity of the CoS particles. However, the potential inter-plane (002) diffraction peak at around $26^{\circ}$ from carbon or graphene in both composite samples is not observable, which could be due to the low carbon content as well as the lower peak intensity of the carbon species compared to that of $\mathrm{CoS}$ in the composites.

As shown in Fig. 1(b), the Raman spectra of composites CoS@C/10Graphene and CoS@C confirm the presence of carbon and graphene in the samples. Both composites exhibit two Raman bands at 1380 and $1580 \mathrm{~cm}^{-1}$, corresponding to the $\mathrm{D}$ and $\mathrm{G}$ bands of disordered carbon and $\mathrm{sp}^{2}$ hybridized graphitic carbon, respectively. 

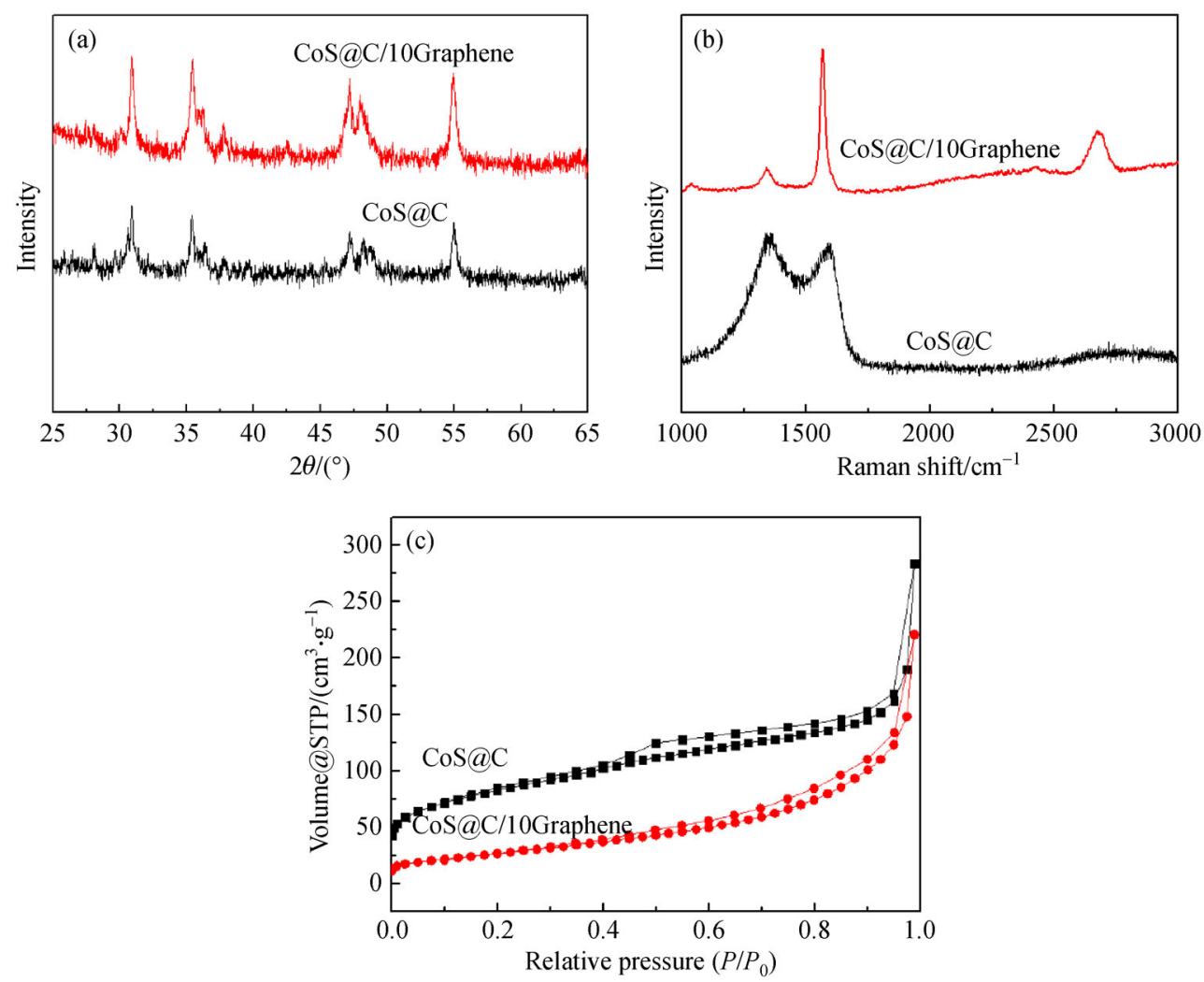

Fig. 1 (a) Powder XRD, (b) Raman spectra and (c) $\mathrm{N}_{2}$ sorption isotherms of $\mathrm{CoS} @ \mathrm{C} / 10$ Graphene and $\operatorname{CoS} @ \mathrm{C}$.

However, both bands in composite CoS@C/10Graphene are much sharper than those in sample $\mathrm{CoS} @ \mathrm{C}$, due to the presence of graphene which was converted from GO during the high temperature heat process. Moreover, the intensity ratio of the $\mathrm{D}$ and $\mathrm{G}$ band $\left(I_{\mathrm{D}} / I_{\mathrm{G}}\right)$ reflects the graphitization degree of carbon in the samples. The $I_{\mathrm{D}} / I_{\mathrm{G}}$ values are 0.1 and 1.08 for $\mathrm{CoS} @ \mathrm{C} / 10 \mathrm{Graphene}$ and CoS@C, respectively, which confirms the presence of highly graphitized carbon (graphene) in the composite CoS@C/10Graphene. In addition, a band at $2690 \mathrm{~cm}^{-1}$ is observed in the Raman spectra of composite CoS@C/ 10Graphene, which is due to the 2D band of graphene and further confirms the presence of graphene in the sample. However, this band is not observable in $\mathrm{CoS} @ \mathrm{C}$, suggesting that only amorphous carbon is presented in sample $\mathrm{CoS} @ \mathrm{C}$, which is consistent with previous report [37].

The TGA profiles and the corresponding MS signals of composites CoS@C/10Graphene and CoS@C in air are shown in Fig. S2 (cf. ESM). In the TGA profiles (Fig. S2 (a)), both $\mathrm{CoS} @ \mathrm{C} / 10 \mathrm{Graphene}$ and $\mathrm{CoS} @ \mathrm{C}$ exhibit similar weight loss event at around $100{ }^{\circ} \mathrm{C}$, which corresponds to the removal of adsorbed moisture from the samples. Both composites display a weight gain event in the temperature range of $300-480{ }^{\circ} \mathrm{C}$ due to the oxidation of the low valance state of $\mathrm{CoS}$ to a high valence state, followed by two remarkable weight loss events in the temperature range of $460-580^{\circ} \mathrm{C}$ and $750-850{ }^{\circ} \mathrm{C}$, which is due to the combustion of the formed amorphous carbon and graphene in the composites and the oxidation of $\mathrm{CoS}$ in air, respectively, as confirmed by the emission of $\mathrm{CO}_{2}$, $\mathrm{SO}_{2}$ and $\mathrm{NO}_{2}$ in their MS signals (Figs. S2(b-d)) [37,47]. Compared to CoS@C, the weight loss event of CoS@C/ 10Graphene shifts to a higher temperature, probably due to the relatively higher burn-off temperature of graphene than that of the amorphous carbon in CoS@C.

The textural properties of composites CoS@C/ 10 graphene and CoS@C measured from $\mathrm{N}_{2}$ sorption are shown in Fig. 1(c). Both samples exhibit type IV isotherms with an obvious hysteresis loop between their adsorption and desorption branches, indicating the presence of mesopores in these composites, which may arise from the voids between particles. The specific surface area of samples CoS@C/10Graphene and CoS@C are 105 and $277 \mathrm{~m}^{2} \cdot \mathrm{g}^{-1}$ and the pore volumes are 0.34 and $0.71 \mathrm{~cm}^{3} \cdot \mathrm{g}^{-1}$, respectively. It is worth noting that the surface area and pore volume of $\mathrm{CoS} @ \mathrm{C} / 10 \mathrm{Graphene}$ are significantly lower than that of $\mathrm{CoS} @ \mathrm{C}$, probably due to the partial blockage of the pore channels of the formed porous carbons by the introduced graphene. Moreover, the surface area and pore volume of these composites are much lower than their precursors, which could be due to the 
collapse of the porous structures during the sulfurization process and the formation of $\mathrm{CoS}$ which increased the mass of the resulting composites.

As shown in Fig. 2, the particle morphologies of the obtained $\mathrm{CoS} / \mathrm{C}$ composite are significantly different from their precursors due to the collapse of ZIF frameworks and the change of the components caused by the high temperature sulfurization process. Both CoS@C/10Graphene and CoS@C are composed of CoS nanoparticles in irregular shape with very small size, but no single CoS particles can be easily observed and most CoS particles are well embedded in the composites. It should be noticed that the graphene in composite CoS@C/10Graphene may be served as a bridge between $\mathrm{CoS}$ particles and the porous carbon. Moreover, high resolution TEM images (Figs. 2(b) and 2(d)) of CoS@C/10Graphene and CoS@C show some pore channels that are visible at the edge of the particles, due to the presence of formed porous carbon. In addition, the lattice of $\mathrm{CoS}$ nanocrystals is observable in the dark area of Figs. 2(b) and 2(d). In the selected area electron diffraction (SAED) patterns of the inset in Figs. 1(a) and 1(c), the bright scattered dots are contributed from the crystalline $\mathrm{CoS}$ nanoparticles, while the dimmed diffraction rings are originated from the amorphous porous carbon matrix.

The SEM images of CoS@C and CoS@C/Graphene are shown in Fig. S3 (cf. ESM). It seems that the CoS@C generally remains the crystal particles similar to its ZIF-67 precursor, but CoS@C/Graphene exhibits more uniform polyhedral particles with average particle size of $0.2 \mu \mathrm{m}$,
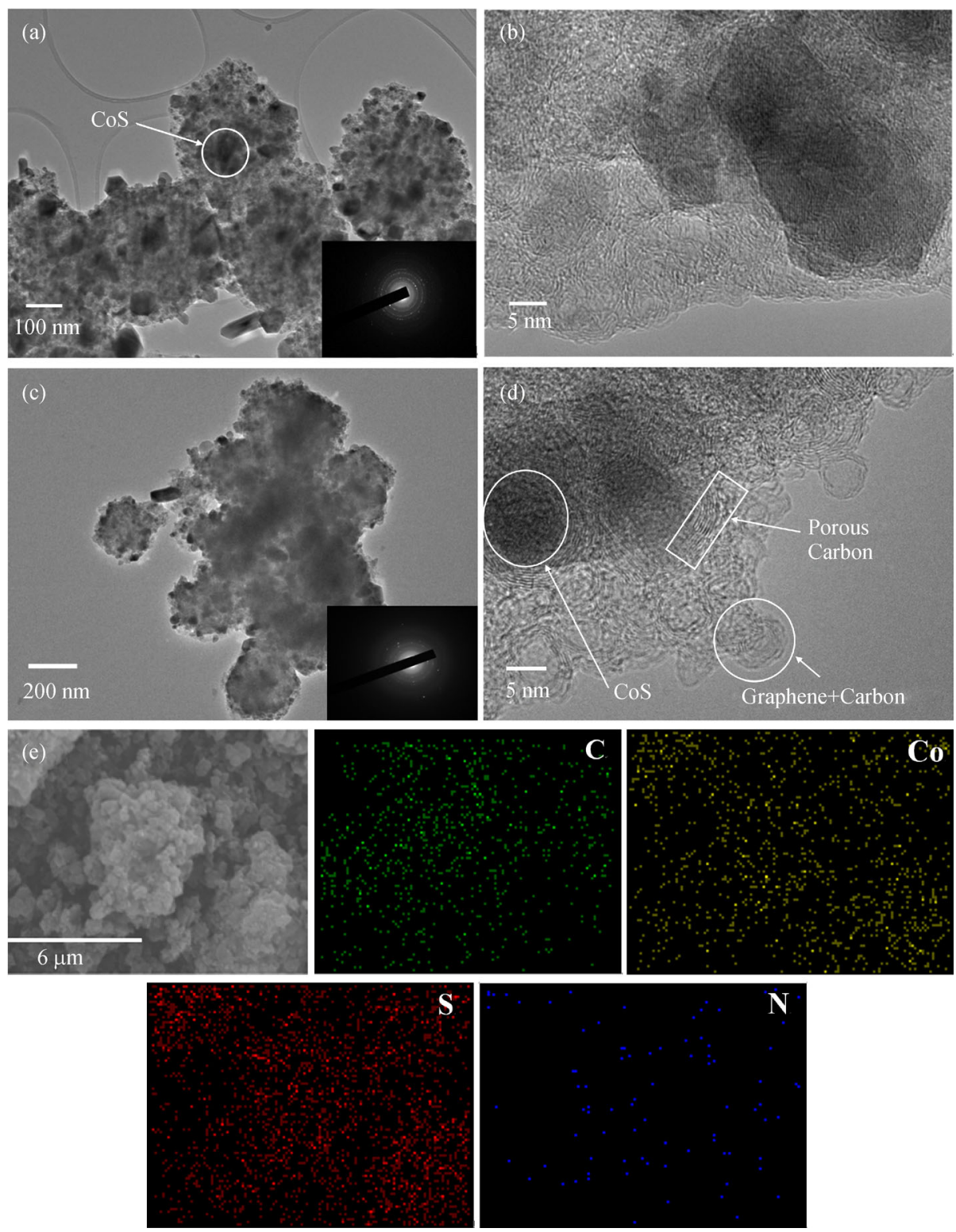

C
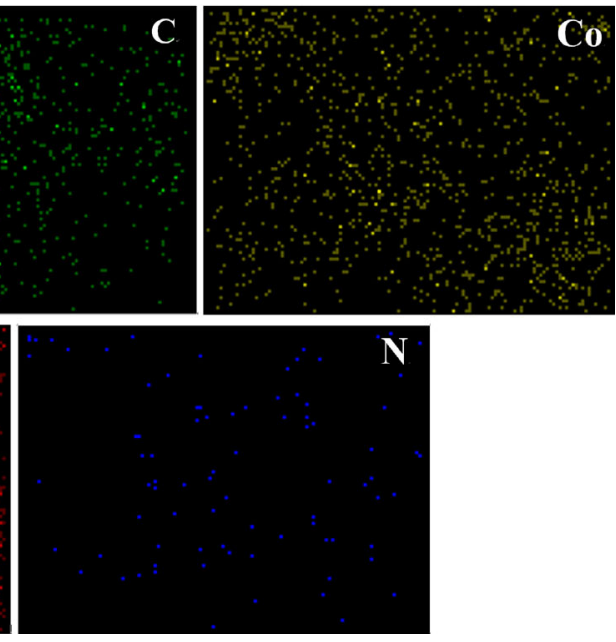

Fig. 2 TEM images of $(\mathrm{a}, \mathrm{b}) \mathrm{CoS} @ \mathrm{C}$ and $(\mathrm{c}, \mathrm{d}) \mathrm{CoS} @ \mathrm{C} / 10 \mathrm{Graphene}$; inset in $(\mathrm{a}, \mathrm{c})$ is SAED patterns for corresponding sample; (e) elemental mappings for CoS@C/10Graphene. 
possibly due to better dispersion of the formed $\mathrm{CoS}$ in the carbon/graphene matrix as a result of the introduced graphene. To investigate the distribution of $\mathrm{CoS}$ particles in the composites, the elemental mapping of sample $\mathrm{CoS} @ \mathrm{C} / 10 \mathrm{Graphene}$ was measured. As shown in Fig. 2(e), all the elements $\mathrm{C}, \mathrm{Co}, \mathrm{S}$ and $\mathrm{N}$ exhibit similar mapping patterns with their selected area of the SEM image, which implies that $\mathrm{CoS}$ nanoparticles are homogeneously dispersed in the carbon/graphene matrix. It is worth noting that a small amount of $\mathrm{N}$ elements was detected, which also further suggests that $\mathrm{N}$-doped carbon matrix were formed in the composites.

The XPS element survey spectra of CoS@C/10Graphene and CoS@C (Fig. 3(a)) show the binding energy peaks at 165, 284, 400, 530 and $778 \mathrm{eV}$, which can be assigned to $\mathrm{S} 2 \mathrm{p}, \mathrm{C} 1 \mathrm{~s}, \mathrm{~N} 1 \mathrm{~s}, \mathrm{O} 1 \mathrm{~s}$ and Co $2 \mathrm{p}$, respectively [48,49]. The high-resolution XPS spectra of C 1s (Fig. 3(b)) of both samples exhibits a strong peak with binding energy at $284.6 \mathrm{eV}$, which arises from the formation of $\mathrm{sp}^{2}$ hybridized graphitic structure [49]. This C 1s peak may be deconvoluted into several peaks located at 284.9, 285.9 and $288.8 \mathrm{eV}$ that are due to $\mathrm{C}=\mathrm{C}, \mathrm{C}-\mathrm{S}$ and $\mathrm{C}-\mathrm{N}$, respectively. The Co $2 p$ (Fig. 3(c)) spectra of both samples display not only the spin-orbit doublets at 782.8 and 798.3 $\mathrm{eV}$, indicating the presence of $\mathrm{Co}^{2+}$ oxidation state in both composites, but also another doublets at 778.8 and 793.5 $\mathrm{eV}$, implying the existence of $\mathrm{Co}^{3+}$ oxidation state. Therefore, both samples possess mixed oxidation states of $\mathrm{Co}^{2+}$ and $\mathrm{Co}^{3+}$, but the $\mathrm{Co} 2 \mathrm{p}$ is dominated with $\mathrm{Co}^{3+}$ state in CoS@C/10Graphene while it is mainly presented as $\mathrm{Co}^{2+}$ states in $\mathrm{CoS} @ \mathrm{C}$. In the S 2p spectra of both samples (Fig. 3(d)), the peaks at 168.5 and $169.7 \mathrm{eV}$ indicate that $\mathrm{CoS}$ compound was formed during the sulfurization process. The two peaks at 161.4 and $162.5 \mathrm{eV}$ were due to the spin-orbit coupling of metal sulfide. No peak at $163.5 \mathrm{eV}$ was observed, suggesting negligible or little $\mathrm{S}$ has been covalently bonded to the porous carbon or graphene in the as-synthesized composites. These results are in agreement with previously reported results [37]. N 1s spectra (Fig. 3(e)) for both samples can be deconvoluted into several peaks: the two peaks at 397.8 and $401.8 \mathrm{eV}$ can be attributed to the pyridinic $\mathrm{N}$ species and quaternary $\mathrm{N}$ species, respectively $[49,50]$. The peak at $400.1 \mathrm{eV}$ corresponds to pyrrolic $\mathrm{N}$ species, which is also consistent with previous report [37].

The electrochemical behavior of the generated nanocmposites toward different electrocatalytic reactions were evaluated and presented in Figs. 4-7. To evaluate the electrocatalytic performance of the two samples for ORR, the $\mathrm{CV}$ was performed in $\mathrm{O}_{2}$ and $\mathrm{N}_{2}$ saturated $0.1 \mathrm{~mol} \cdot \mathrm{L}^{-1}$ $\mathrm{KOH}$ solution at $25{ }^{\circ} \mathrm{C}$, respectively. As shown in Fig. 4(a), no obvious redox peak for both samples is observed in $\mathrm{N}_{2}$-saturated $\mathrm{KOH}$ solution. However, when the solution is saturated with $\mathrm{O}_{2}$, both samples exhibit remarkable ORR activity associated with a well-defined cathodic peak at potential of $\sim 0.80 \mathrm{~V}$ ( $v s$. RHE). Moreover, sample CoS@C/10Graphene reveals a significant higher peak current $\left(-2.89 \mathrm{~mA} \cdot \mathrm{cm}^{-2}\right)$ than that of CoS@C $\left(-1.7 \mathrm{~mA} \cdot \mathrm{cm}^{-2}\right)$, which indicates the much enhanced ORR activity of sample CoS@C/10Graphene compared to CoS@C.

To get further insight into the ORR kinetics of the two samples, LSV measurements were carried out with RDE at different rotating speeds and their kinetic parameters were calculated based on the Koutecky-Levich (K-L) equation. Both samples show an increase in current density with increasing rotation speeds (as shown in Figs. 4(b) and 4(d)), which is due to the enhanced diffusion of oxygen on the electrode surface at higher rotation speeds. Compared to sample CoS@C, the K-L plots of sample CoS@C/10Graphene (Figs. 4(c) and 4(e)) are much more compact with good linearity and parallelism properties, suggesting a first-order reaction kinetics. This observation also indicates that introduction of graphene into the composite is beneficial to the oxygen reaction and maintains high electron transfer numbers $(n)$ for ORR at various potentials. As presented in Fig. 4(e), the $n$ value of $\mathrm{CoS} @ \mathrm{C} / 10 \mathrm{Graphene}$ for ORR is calculated to be 3.77 to 3.94 in the potential range from 0.23 to $0.63 \mathrm{~V}$ (vs. RHE). In contrast, the $n$ value of the composite CoS@C varies from 3.56 to 3.73 . The $n$ values of these two samples indicate that ORR processed through a four-electron pathway and the graphene plays an important role in achieving higher $n$ value. Moreover, the kinetic current density $J_{\mathrm{k}}$ of $\mathrm{CoS} @ \mathrm{C} / 10 \mathrm{Graphene}$ is around 15.5-15.7 $\mathrm{mA} \cdot \mathrm{cm}^{-2}$, which is much higher than that of composite CoS@C (in the range of 7.2-9.5 $\mathrm{mA} \cdot \mathrm{cm}^{-2}$ ), indicating that the presence of graphene in the composite improves the electron transfer kinetics of oxygen reduction. In addition, as shown in Fig. $\mathrm{S} 4$ (cf. ESM), the measured $\mathrm{H}_{2} \mathrm{O}_{2}$ yields were below 22\% and 5.8\% for CoS@C and CoS@C/ 10Graphene, respectively. The corresponding $n$ values calculated from the $\mathrm{H}_{2} \mathrm{O}_{2}$ yields are 3.56-3.64 for sample CoS@C and 3.88-3.90 for CoS@C/10Graphene in the potential range of $0.23-0.63 \mathrm{~V}$, which are well consistent with the results obtained from the K-L plots. CoS@C/ 10Graphene exhibits significantly higher $n$ value and higher $J_{\mathrm{k}}$ value than that of $\mathrm{CoS} @ \mathrm{C}$, suggesting that both samples proceed mainly via a four-electrode ORR process, but CoS@C/10Graphene has better kinetics characteristics than CoS@C, possibly due to the good electrical conductivity of the introduced graphene as well as the formation of extra active sites associated with $\mathrm{N}$ or $\mathrm{S}$ doped graphene.

The ORR polarization curves at $1600 \mathrm{r} \cdot \mathrm{min}^{-1}$ in $0.1 \mathrm{~mol} \cdot \mathrm{L}^{-1} \mathrm{KOH}$ of $\mathrm{CoS} @ \mathrm{C} / 10 \mathrm{Graphene}, \mathrm{CoS} @ \mathrm{C}$ and commercial $\mathrm{Pt} / \mathrm{C}$ are presented in Fig. 5(a). Both CoS@C/10Graphene and CoS@C hold very similar onset potential at 0.87 and $0.86 \mathrm{~V}$ respectively, which is close to the onset potential of the commercial $\mathrm{Pt} / \mathrm{C}(0.95 \mathrm{~V})$, suggesting that both samples are good electrocatalysts for ORR. However, the cathodic current density of CoS@C/10Graphene $\left(-4.2 \mathrm{~mA} \cdot \mathrm{cm}^{-2}\right)$ is higher than 

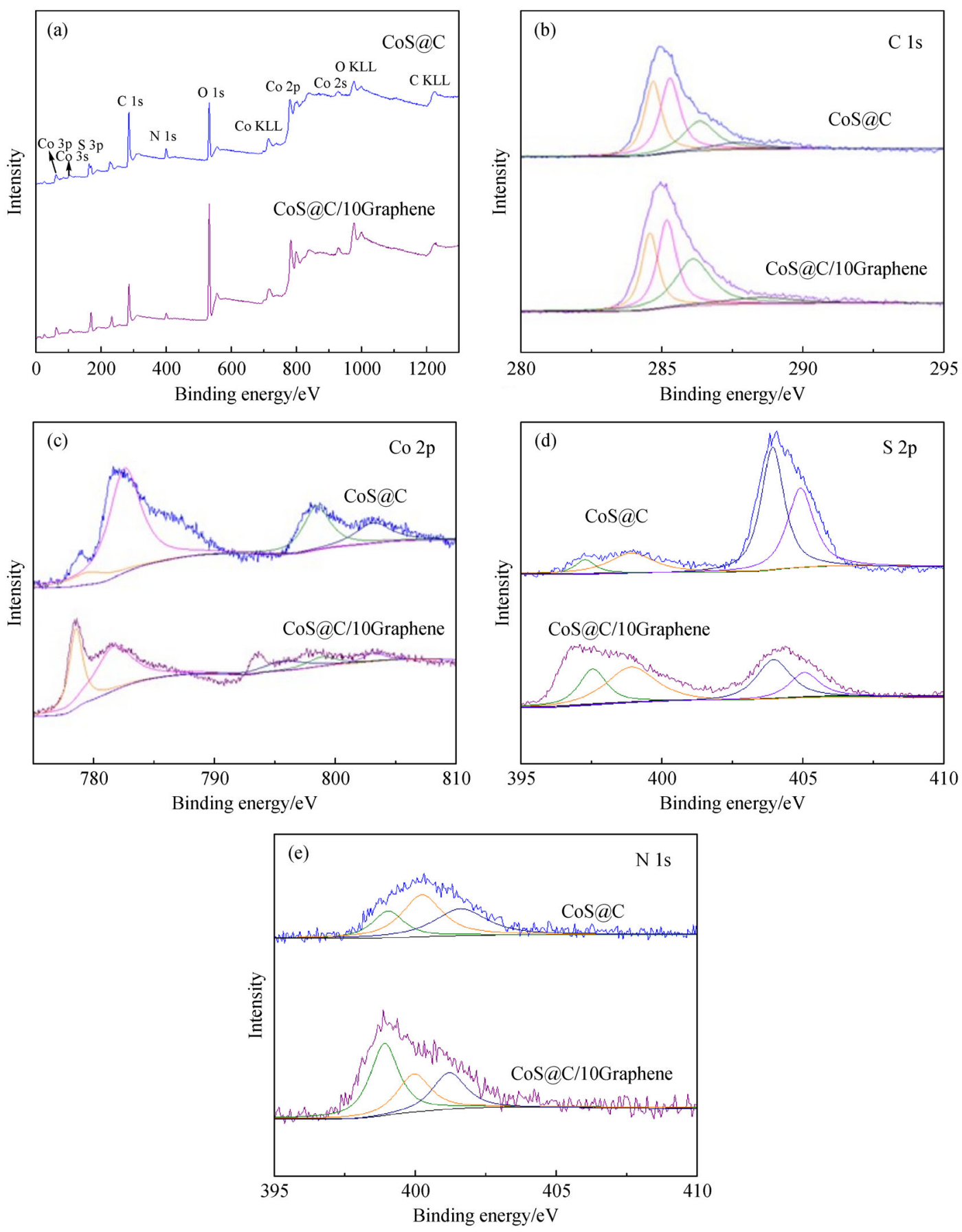

Fig. 3 (a) Element survey by XPS and high resolution XPS spectra of (b) C 1s, (c) Co 2p, (d) S 2p and (e) N 1s of CoS@C and CoS@C/10Graphene.

that of CoS@C $\left(-3.7 \mathrm{~mA} \cdot \mathrm{cm}^{-2}\right)$, implying that CoS@C/10Graphene is a more active ORR electrocatalyst than CoS@C, maybe due to the improved electrical conductivity by the introduced graphene in the composite CoS@C/10Graphene. Moreover, CoS@C/10Graphene exhibits excellent electrochemical stability at a constant polarizing potential of $-0.15 \mathrm{~V}$ in $0.1 \mathrm{~mol} \cdot \mathrm{L}^{-1} \mathrm{KOH}$, with a very small current decay (2\%) after continuously running of 4.86 h (as shown in Fig. 5(b)). In contrast, CoS@C and the benchmark $\mathrm{Pt} / \mathrm{C}$ catalyst exhibits a current decay of $13 \%$ and $26 \%$, respectively under the same conditions. Therefore, the stability of CoS@C/10Graphene toward ORR is superior. In addition, the methanol tolerance of CoS@C/10Graphene, CoS@C and Pt/C under the same conditions was also investigated, which is shown in Fig. 5(c). The results show that the introduction of 

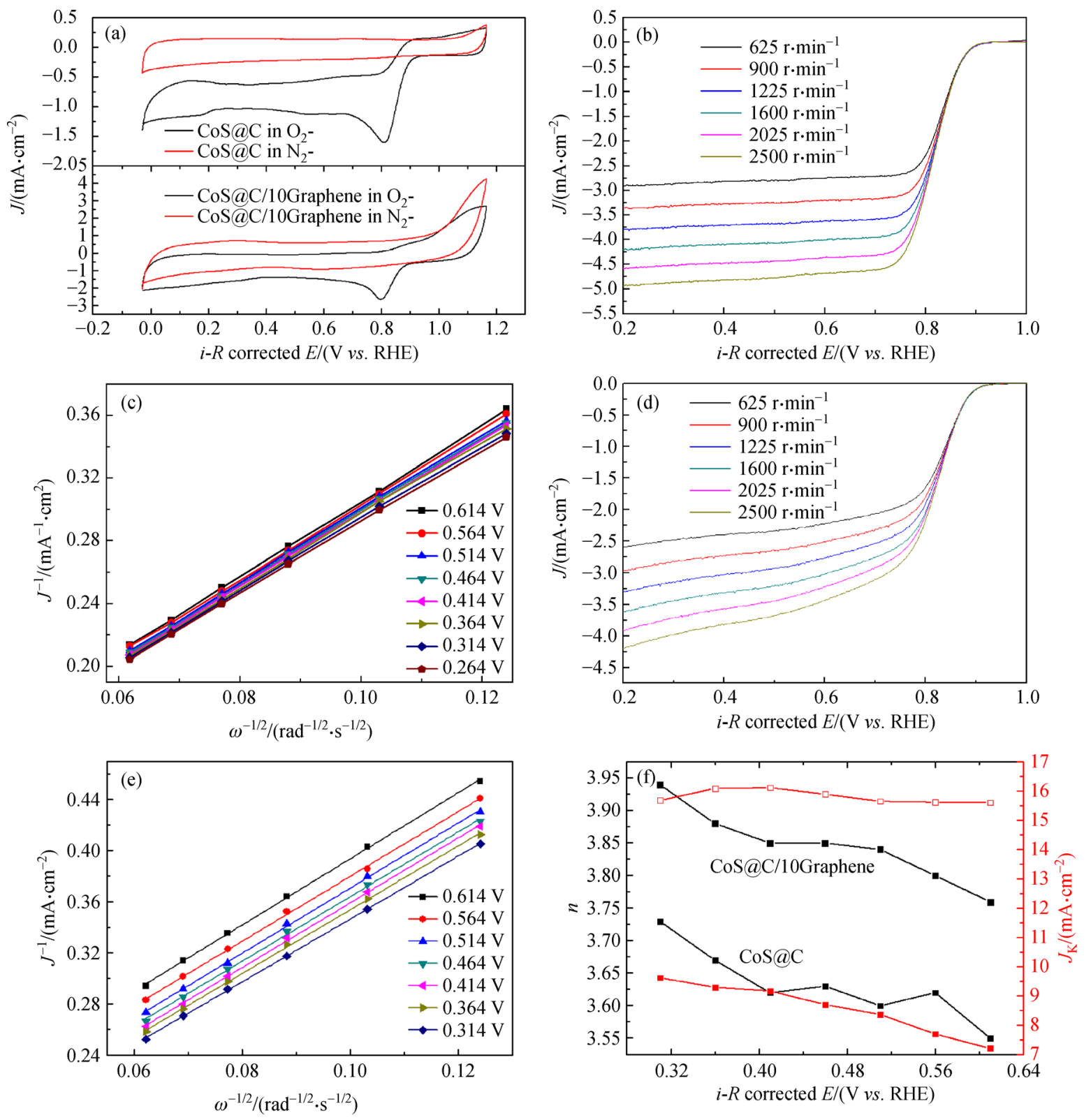

Fig. 4 (a) CV curves of $\mathrm{CoS} @ \mathrm{C}$ and $\mathrm{CoS} @ \mathrm{C} / 10 \mathrm{Graphene}$ in $\mathrm{N}_{2}$ - or $\mathrm{O}_{2}$-saturated $0.1 \mathrm{~mol} \cdot \mathrm{L}^{-1} \mathrm{KOH}$; (b, d) ORR polarization curves of CoS@C/10Graphene and CoS@C at different rotating speeds, respectively; (c, e) K-L plots of samples CoS@C/10Graphene and CoS@C at different potentials, respectively; (f) $n$ and the corresponding $J_{\mathrm{k}}$ of $\mathrm{CoS} @ \mathrm{C} / 10 \mathrm{Graphene}$ and $\mathrm{CoS} @ \mathrm{C}$ as a function of the electrode potentials.

methanol causes a sharp decrease in the current density of the $\mathrm{Pt} / \mathrm{C}$ catalyst. However, methanol has negligible effect on the performance of $\mathrm{CoS} @ \mathrm{C} /$ Graphene and CoS@C. The remarkable electrocatalytic activity, superior durability and good methanol tolerance suggest CoS@C/10Graphene is a promising electrocatalyst for ORR.

The difference in the activity and durability toward ORR between CoS@C/10Graphene and CoS@C is related to the presence of graphene in sample CoS@C/10Graphene, which facilitates the electron and mass transfer, thus accelerates the ORR process and improves the durability. First, the graphene with excellent electronic conductivity could serve as a bridge between $\mathrm{CoS}$ particles embedded in the porous carbon to improve the connectivity, which favors the carrier transfer. Secondly, $\mathrm{N}$ and/or S are doped into the carbon/graphene during the sulfurization and carbonization process to form $\mathrm{CoS} @ \mathrm{C} / 10 \mathrm{Graphene}$, which could not only offer more electrocatalytic active sites for ORR reaction, but also provide anchoring sites for catalytical CoS nanoparticle deposition. 

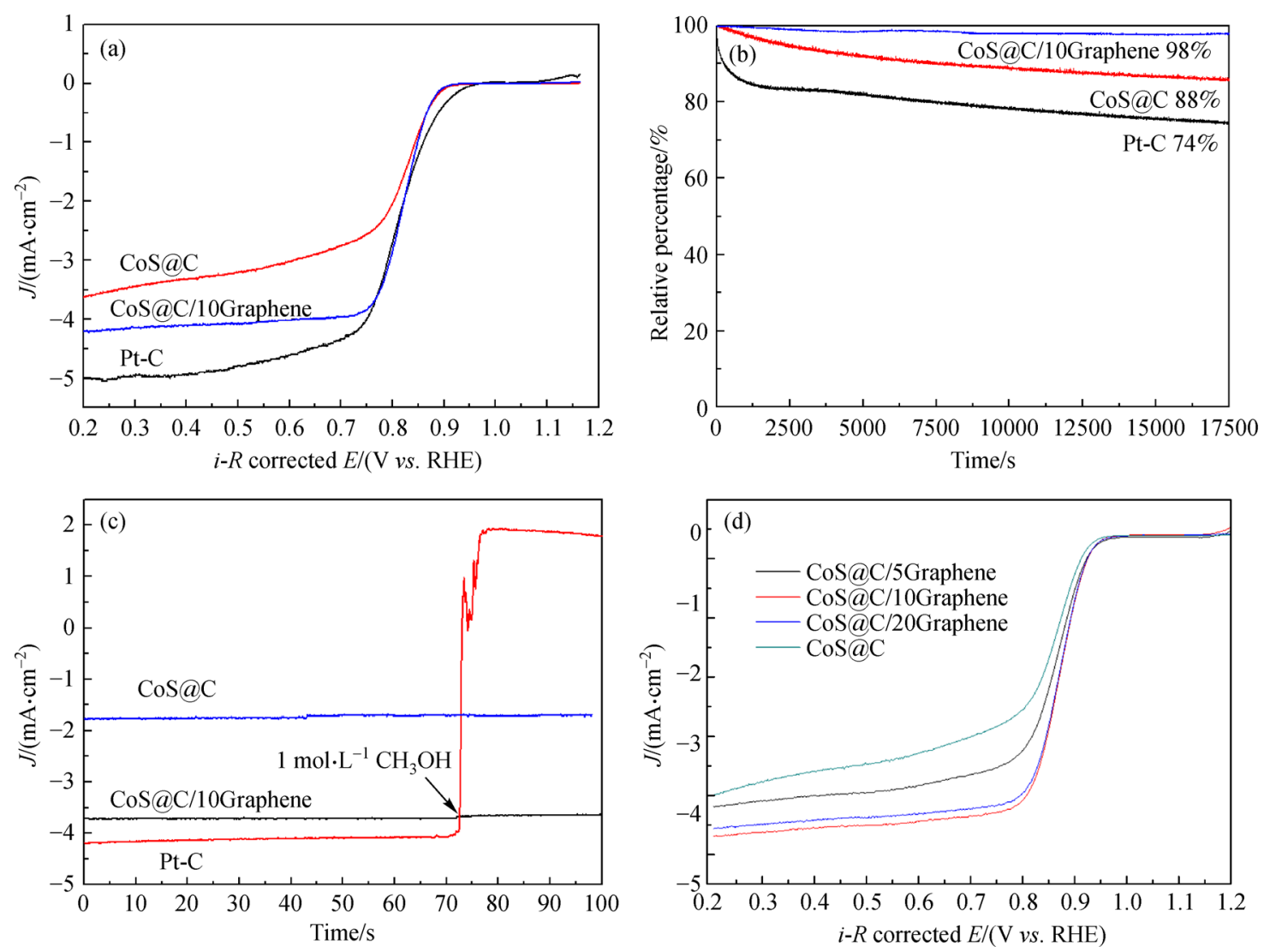

Fig. 5 (a) ORR polarization curves and (b) current-time chronoamperometric responses of CoS@C/10Graphene, CoS@C and Pt/C at $1600 \mathrm{r} \cdot \mathrm{min}^{-1}$ in $\mathrm{O}_{2}$-saturated $0.1 \mathrm{~mol} \cdot \mathrm{L}^{-1} \mathrm{KOH}$ solution; (c) chronoamperometric responses of $\mathrm{CoS} @ \mathrm{C} / 10 \mathrm{Graphene}, \mathrm{CoS} @ \mathrm{C}$ and $\mathrm{Pt} / \mathrm{C}$ at $-0.15 \mathrm{~V}$ in $\mathrm{O}_{2}$-saturated $0.1 \mathrm{~mol} \cdot \mathrm{L}^{-1} \mathrm{KOH}$ solution $\left(1600 \mathrm{r} \cdot \mathrm{min}^{-1}\right.$ ) with $1 \mathrm{~mol} \cdot \mathrm{L}^{-1}$ methanol; (d) ORR polarization curves of $\mathrm{CoS} @ \mathrm{C} / \mathrm{Graphene}$ composites with various graphene content.

To determine the effect of graphene content on the performance of the obtained CoS@C/Graphene composites for ORR, various graphene contents were introduced into the composites and their ORR polarization curves are presented in Fig. 5(d). Although these CoS@C/Graphene composites with different graphene contents exhibited very similar onset potential to $\mathrm{CoS} @ \mathrm{C}$, they exclusively showed higher half-wave potentials than CoS@C. Moreover, sample CoS@C/10Graphene displayed the highest ORR activity among the studied CoS@C/Graphene composites with different graphene contents. These results further indicate that the graphene in the composites plays an important role in enhancing the electrocatalytic activity toward ORR.

Besides the excellent electrocatalytic activity for ORR, CoS@C/10Graphene also exhibits good performance toward OER. As shown in Fig. 6(a), the LSV polarization curve of CoS@C/10Graphene shows higher current density and a higher onset of catalytic current compared to CoS@C. To achieve the current density of $10 \mathrm{~mA} \cdot \mathrm{cm}^{-2}$, sample CoS@C/10Graphene requires an overpotential of $1.68 \mathrm{~V}$ ( $v s$. RHE), which is much lower than that of $\mathrm{CoS} @ \mathrm{C}(1.86 \mathrm{~V} v s . \mathrm{RHE})$ and only $0.1 \mathrm{~V}$ higher than that of the benchmark $\mathrm{IrO}_{2}(1.58 \mathrm{~V} v s$. RHE) catalyst for
OER. Pt/C requires a much higher overpotential to reach current density of $10 \mathrm{~mA} \cdot \mathrm{cm}^{-2}$, suggesting it is not a good OER catalyst. The performance improvement of CoS@C/10Graphene toward OER is contributed by the introduced graphene, which not only facilitates the adsorption of $\mathrm{OH}$ ions, but also provides more access pathways as well as promotes the electron transfer between the catalyst surface and the reaction intermediates. Furthermore, the durability of sample CoS@C/10Graphene in OER was also evaluated via current-time chronoamperometric test. As shown in Fig. 6(b), after continuously running for $4.17 \mathrm{~h}(15000 \mathrm{~s})$ in $0.1 \mathrm{~mol} \cdot \mathrm{L}^{-1}$ $\mathrm{KOH}$ solution, CoS@C/10Graphene exhibits an initial performance loss of $15 \%$ at the first $5000 \mathrm{~s}$, then stabilizes at $85 \%$ of its initial current density, suggesting good durability.

Apart from the ORR and OER activities, the graphene reinforced CoS@C/10Graphene composite also exhibits electrocatalytic activities toward electrochemical HER, an important way for hydrogen generation along with photocatalytic hydrogen production [51,52]. The HER performance of $\mathrm{CoS} @ \mathrm{C}$ and $\mathrm{CoS} @ \mathrm{C} / 10 \mathrm{Graphene}$ was evaluated using a three-electrode system in $0.5 \mathrm{~mol} \cdot \mathrm{L}^{-1}$ $\mathrm{H}_{2} \mathrm{SO}_{4}$ solution. For comparison, the commercial $20 \mathrm{wt}-\%$ 

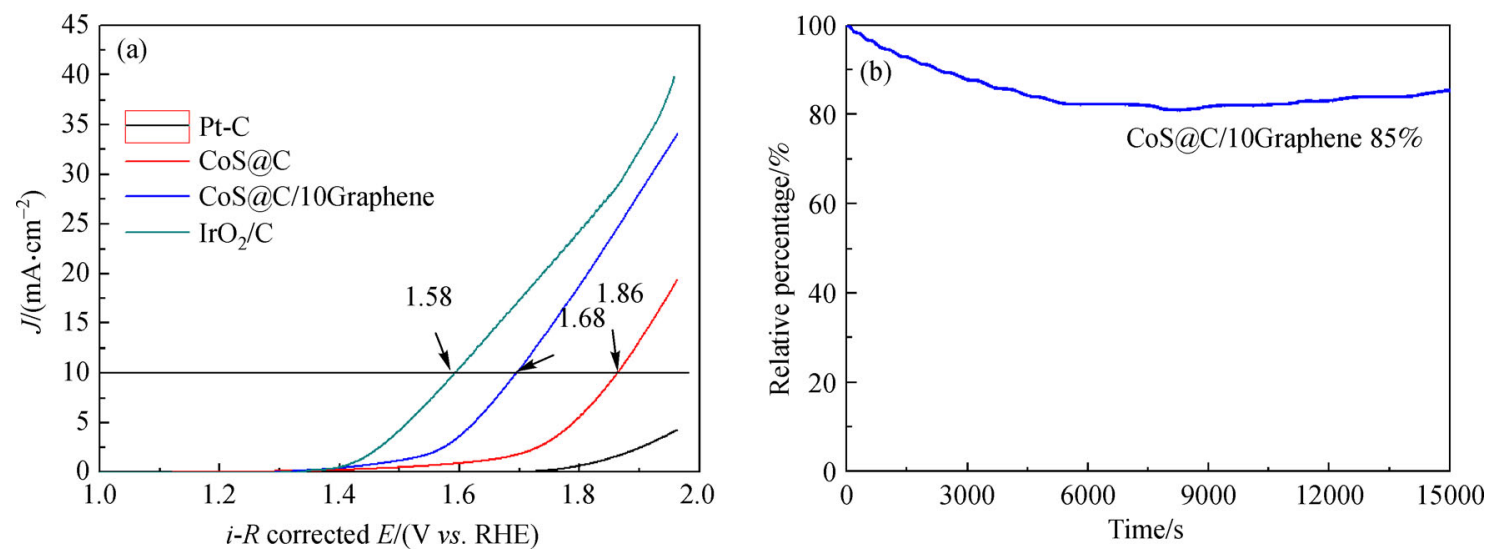

Fig. 6 (a) LSV polarization curves of $\mathrm{CoS} @ \mathrm{C} / 10 \mathrm{Graphene,} \mathrm{CoS} @ \mathrm{C}$ and Pt/C; (b) current-time chronoamperometric responses of $\mathrm{CoS} @ \mathrm{C} / 10 \mathrm{Graphene}$ measured in $0.1 \mathrm{~mol} \cdot \mathrm{L}^{-1} \mathrm{KOH}$ solution.

$\mathrm{Pt} / \mathrm{C}$ was examined as control. As shown in Fig. 7(a), the polarization curve of $\mathrm{CoS} @ \mathrm{C} / 10 \mathrm{Graphene}$ exhibits an onset potential of $-0.28 \mathrm{~V}$, which is lower than that of CoS@C $(-0.3 \mathrm{~V})$. To achieve the current density of $-10 \mathrm{~mA} \cdot \mathrm{cm}^{-2}$, a potential of $-0.45 \mathrm{~V}$ is needed for sample $\mathrm{CoS} @ \mathrm{C}$, whereas only $-0.42 \mathrm{~V}$ is required for composite CoS@C/10Graphene. However, the HER performances of these composites is in general still inferior to the benchmark 20\% Pt/C sample. The Tafel plots of these samples for HER are constructed based on the corresponding LSV curves and presented in Fig. 7(b). CoS@C/10Graphene displays a slope of $80 \mathrm{mV} \cdot \mathrm{dec}^{-1}$, which is much lower than that of CoS@C $\left(93 \mathrm{mV} \cdot \mathrm{dec}^{-1}\right)$. This observation further confirms that CoS@C/10Graphene is a better electrocatalyst toward HER compared to $\mathrm{CoS} @ \mathrm{C}$, indicating that the presence of graphene benefits the enhancement of the HER performance of the composite due to the excellent conductivity of graphene.

The above electrochemical results suggest that the graphene-reinforced MOF-derived composites CoS@C/ Graphene are efficient trifunctional electrocatalysts which exhibit good electrochemical activities for ORR, OER and HER. In particular, CoS@C/10Graphene is a promising multifunctional electrocatalyst with excellent electrocatalytic performance toward ORR, OER and HER. The enhanced electrocatalytic activities of the graphenereinforced $\mathrm{CoS} / \mathrm{C}$ nanocomposites are due to the following reasons. On one hand, the N, S co-doped porous carbons and graphene derived from sulfurization and carbonization of in situ as-synthesized GO-ZIF-67 precursor, can provide more accessible active sites and promote catalyst structural stability; on the other hand, the introduction of graphene by the reduction of GO in the carbonization process of the GO-ZIF-67 can increase the electrical conductivity and improve the electron and charge transfer between the catalyst surface and the reaction intermediates.

\section{Conclusions}

In summary, we present a simple and facile method to prepare $\mathrm{CoS}$ on $\mathrm{N}, \mathrm{S}$ co-doped porous carbon and graphene
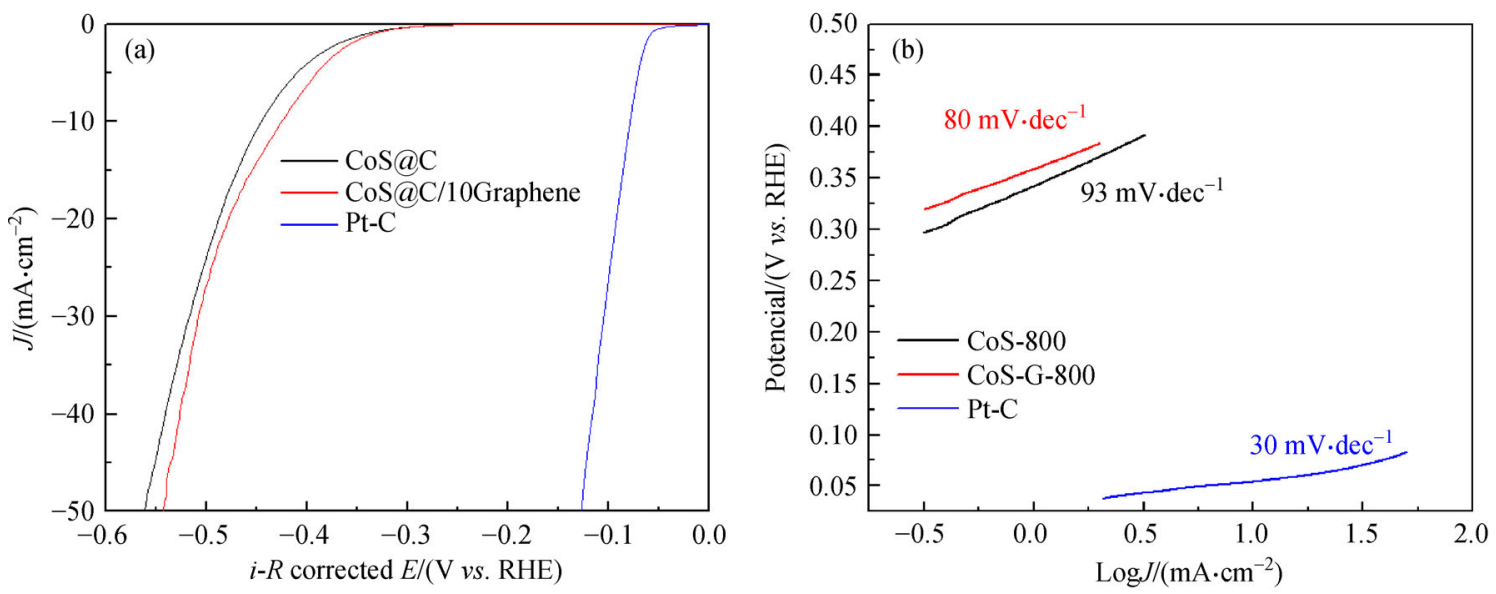

Fig. 7 (a) Polarization curves and (b) corresponding Tafel plots of $\mathrm{CoS} @ \mathrm{C}, \mathrm{CoS} @ \mathrm{C} / 10 \mathrm{Graphene}$ and Pt/C for HER measured in $0.5 \mathrm{~mol} \cdot \mathrm{L}^{-1} \mathrm{H}_{2} \mathrm{SO}_{4}$ solution. 
nanocomposites $\mathrm{CoS} @ \mathrm{C} /$ Graphene by high temperature treatment of the one-pot synthesized GO-ZIF67 precursors in $\mathrm{H}_{2} \mathrm{~S}$ atmosphere. Various characterization techniques were used to analyze the physiochemical properties of the obtained CoS@C/10Graphene nanocomposites. The CoS nanoparticles were homogenously dispersed in the in situ formed porous carbon and graphene matrix. Moreover, heteroatoms $\mathrm{N}, \mathrm{S}$ elements were successfully doped into porous carbon and graphene in the composites. The CoS@C/Graphene composites exhibit not only excellent activity and durability for ORR, but also good performance for OER and HER. The introduction of graphene into the composites together with the co-doping of $\mathrm{N}$ and $\mathrm{S}$ to graphene and the in situ formed porous carbon, effectively provide more catalytic active sites, increase the electrical conductivity as well as the connectivity between electrocatalytic active $\mathrm{CoS}$ and carbon matrix, and facilitate electron and charge transportation, which consequently render the $\mathrm{CoS} @ \mathrm{C} / \mathrm{Graphene}$ composites promising electrocatalysts for relevant energy storage and conversion applications.

Acknowledgements The authors thank EPSRC CDT in Metamaterials at the University of Exeter and Leverhulme Trust (Grant No. RPG-2018-320) for financial support.

Electronic Supplementary Material Supplementary material is available in the online version of this article at https://doi.org/10.1007/s11705-0212085-3 and is accessible for authorized users.

Open Access This article is licensed under a Creative Commons Attribution 4.0 International License, which permits use, sharing, adaptation, distribution and reproduction in any medium or format, as long as you give appropriate credit to the original author(s) and the source, provide a link to the Creative Commons licence, and indicate if changes were made. The images or other third party material in this article are included in the article's Creative Commons licence, unless indicated otherwise in a credit line to the material. If material is not included in the article's Creative Commons licence and your intended use is not permitted by statutory regulation or exceeds the permitted use, you will need to obtain permission directly from the copyright holder. To view a copy of this licence, visit http://creativecommons.org/licenses/by/4.0/.

\section{References}

1. Borge-Diez D, Rosales-Asensio E. Energy Services Fundamentals and Financing. 1st ed. Cambridge: Academic Press, 2020, 155-179

2. Brandt K, Garche J. Electrochemical Power Sources: Fundamentals, Systems, and Applications. 1st ed. Amsterdam: Elsevier, 2018, 1-19

3. Ouyang T, Ye Y Q, Wu C, Xiao K, Liu Z. Heterostructures composed of $\mathrm{N}$-doped carbon nanotubes encapsulating cobalt and$\mathrm{Mo}_{2} \mathrm{C}$ nanoparticles as bifunctional electrodes for water splitting. Angewandte Chemie International Edition, 2019, 58(15): 49234928

4. Liu Z Q, Ouyang T, Wang X T, Mai X Q, Chen A N, Tang Z Y. Coupling magnetic single-crystal $\mathrm{Co}_{2} \mathrm{Mo}_{3} \mathrm{O}_{8}$ with ultrathin nitrogen-rich carbon layer for oxygen evolution reaction. Angewandte Chemie International Edition, 2020, 132(29): 12046-12055

5. Zhang J, Xia Z, Dai L. Carbon-based electrocatalysts for advanced energy conversion and storage. Science Advances, 2015, 1(7): e1500564

6. Peng L, Wei Z. Catalyst engineering for electrochemical energy conversion from water to water: water electrolysis and the hydrogen fuel cell. Engineering, 2020, 6(6): 653-679

7. Zhao D, Zhuang Z, Cao X, Zhang C, Peng Q, Chen C, Li Y. Atomic site electrocatalysts for water splitting, oxygen reduction and selective oxidation. Chemical Society Reviews, 2020, 49(7): 2215-2264

8. Ren X, Lv Q, Liu L, Liu B, Wang Y, Liu A, Wu G. Current progress of Pt and Pt-based electrocatalysts used for fuel cells. Sustainable Energy \& Fuels, 2020, 4(1): 15-30

9. Wang X, Li Z, Qu Y, Yuan T, Wang W, Wu Y, Li Y. Review of metal catalysts for oxygen reduction reaction: from nanoscale engineering to atomic design. Chem, 2019, 5(6): 1486-1511

10. Kong F, Ren Z, Norouzi Banis M, Du L, Zhou X, Chen G, Zhang L, Li J, Wang S, Li M, et al. Active and stable Pt-Ni alloy octahedra catalyst for oxygen reduction via near-surface atomical engineering. ACS Catalysis, 2020, 10(7): 4205-4214

11. Kim M, Park J, Kang M, Kim J Y, Lee S W. Toward efficient electrocatalytic oxygen evolution: emerging opportunities with metallic pyrochlore oxides for electrocatalysts and conductive supports. ACS Central Science, 2020, 6(6): 880-891

12. Lin Y, Tian Z, Zhang L, Ma J, Jiang Z, Deibert B J, Ge R, Chen L. Chromium-ruthenium oxide solid solution electrocatalyst for highly efficient oxygen evolution reaction in acidic media. Nature Communications, 2019, 10(1): 162

13. Reier T, Oezaslan M, Strasser P. Electrocatalytic oxygen evolution reaction (OER) on $\mathrm{Ru}$, Ir, and Pt catalysts: a comparative study of nanoparticles and bulk materials. ACS Catalysis, 2012, 2(8): 17651772

14. Zhao H, Yuan Z Y. Surface/interface engineering of high-efficiency noble metal-free electrocatalysts for energy-related electrochemical reactions. Journal of Energy Chemistry, 2021, 54: 89-104

15. Wang X T, Ouyang T, Wang L, Zhong J H, Liu Z Q. Surface reorganization on electrochemically-induced $\mathrm{Zn}-\mathrm{Ni}$-Co spinel oxides for enhanced oxygen electrocatalysis. Angewandte Chemie International Edition, 2020, 59(16): 6492-6499

16. Hu C, Dai Q, Dai L. Multifunctional carbon-based metal-free catalysts for advanced energy conversion and storage. Cell Reports Physical Science, 2021, 2(2): 100328

17. Hu C, Xiao Y, Zou Y, Dai L. Carbon-based metal-free electrocatalysis for energy conversion, energy storage, and environmental protection. Electrochemical Energy Reviews, 2018, 1(1): 84-112

18. Li S, Hao X, Abudula A, Guan G. Nanostructured Co-based bifunctional electrocatalysts for energy conversion and storage: current status and perspectives. Journal of Materials Chemistry. A, Materials for Energy and Sustainability, 2019, 7(32): 18674-18707

19. Badruzzaman A, Yuda A, Ashok A, Kumar A. Recent advances in cobalt based heterogeneous catalysts for oxygen evolution reaction. Inorganica Chimica Acta, 2020, 511: 119854

20. Guo H, Feng Q, Zhu J, Xu J, Li Q, Liu S, Xu K, Zhang C, Liu T. Cobalt nanoparticle-embedded nitrogen-doped carbon/carbon nanotube frameworks derived from a metal-organic framework for trifunctional ORR, OER and HER electrocatalysis. Journal of 
Materials Chemistry. A, Materials for Energy and Sustainability, 2019, 7(8): 3664-3672

21. Huang Z, Yang Z X, Hussain M Z, Chen B L, Jia Q L, Zhu Y Q, Xia Y D. Polyoxometallates@zeolitic-imidazolate-framework derived bimetallic tungsten-cobalt sulfide/porous carbon nanocomposites as efficient bifunctional electrocatalysts for hydrogen and oxygen evolution. Electrochimica Acta, 2020, 330: 135335

22. Ren J T, Yuan Z Y. Bifunctional electrocatalysts of cobalt sulfide nanocrystals in situ decorated on N,S-codoped porous carbon sheets for highly efficient oxygen electrochemistry. ACS Sustainable Chemistry \& Engineering, 2019, 7(11): 10121-10131

23. Ren J T, Wang Y S, Chen L, Gao L J, Tian W W, Yuan Z Y. Binary FeNi phosphides dispersed on N,P-doped carbon nanosheets for highly efficient overall water splitting and rechargeable $\mathrm{Zn}$-air batteries. Chemical Engineering Journal, 2020, 389: 124408

24. Zhang J W, Zhang H, Ren T Z, Yuan Z Y, Bandosz T J. FeNi doped porous carbon as an efficient catalyst for oxygen evolution reaction. Frontiers of Chemical Science and Engineering, 2021, 15(2): 279 287

25. Tian W W, Ren J T, Lv X W, Gao L J, Yuan Z Y. In situ sulfidation for controllable heterointerface of cobalt oxides-cobalt sulfides on 3D porous carbon realizing efficient rechargeable liquid-/solid-state Zn-air batteries. ACS Sustainable Chemistry \& Engineering, 2021, 9(1): 510-520

26. Lv X W, Liu Y P, Tian W W, Gao L J, Yuan Z Y. Aluminum and phosphorus codoped "superaerophobic" $\mathrm{Co}_{3} \mathrm{O}_{4}$ microspheres for highly efficient electrochemical water splitting and $\mathrm{Zn}$-air batteries. Journal of Energy Chemistry, 2020, 50: 324-331

27. Cai Z X, Wang Z L, Kim J, Yamauchi Y. Hollow functional materials derived from metal-organic frameworks: synthetic strategies, conversion mechanisms, and electrochemical applications. Advanced Materials, 2019, 31(11): 1804903

28. Lee K J, Lee J H, Jeoung S, Moon H R. Transformation of metalorganic frameworks/coordination polymers into functional nanostructured materials: experimental approaches based on mechanistic insights. Accounts of Chemical Research, 2017, 50(11): 2684-2692

29. Wang K, Huang X, Zhou T, Wang H, Xie H, Ren Y. Boosted electrochemical properties of porous $\mathrm{Li}_{2} \mathrm{FeSiO}_{4} / \mathrm{C}$ based on $\mathrm{Fe}-$ MOFs precursor for lithium ion batteries. Vacuum, 2020, 171: 108997

30. Zhang X, Chen A, Zhong M, Zhang Z, Zhang X, Zhou Z, Bu X H. Metal-organic frameworks (MOFs) and MOF-derived materials for energy storage and conversion. Electrochemical Energy Reviews, 2019, 2(1): 29-104

31. Huang Z, Yang Z X, Hussain M Z, Jia Q L, Zhu Y Q, Xia Y D. Bimetallic Fe-Mo sulfide/carbon nanocomposites derived from phosphomolybdic acid encapsulated in MOF for efficient hydrogen generation. Journal of Materials Science and Technology, 2021, 84: 76-85

32. Sun Y, Zheng L, Yang Y, Qian X, Fu T, Li X, Yang Z, Yan H, Cui C, Tan W. Metal-organic framework nanocarriers for drug delivery in biomedical applications. Nano-Micro Letters, 2020, 12(1): 103

33. Chen B L, Ma G P, Zhu Y Q, Wang J B, Xiong W, Xia Y D. Metalorganic-framework-derived bi-metallic sulfide on N,S-codoped porous carbon nanocomposites as multifunctional electrocatalysts. Journal of Power Sources, 2016, 334: 112-119
34. Adhikari C, Das A, Chakraborty A. Zeolitic imidazole framework (ZIF) nanospheres for easy encapsulation and controlled release of an anticancer drug doxorubicin under different external stimuli: a way toward smart drug delivery system. Molecular Pharmaceutics, 2015, 12(9): 3158-3166

35. Chen L, Wang H F, Li C, Xu Q. Bimetallic metal-organic frameworks and their derivatives. Chemical Science (Cambridge), 2020, 11(21): 5369-5403

36. Cheng N, Ren L, Xu X, Du Y, Dou S. Recent development of zeolitic imidazolate frameworks (ZIFs) derived porous carbon based materials as electrocatalysts. Advanced Energy Materials, 2018, 8(25): 1801257

37. Chen B L, Li R, Ma G P, Gou X L, Zhu Y Q, Xia Y D. Cobalt sulfide/N,S codoped porous carbon core-shell nanocomposites as superior bifunctional electrocatalysts for oxygen reduction and evolution reactions. Nanoscale, 2015, 7(48): 20674-20684

38. Wang X T, Ouyang T, Wang L, Zhong J H, Ma T, Liu Z Q. Redoxinert $\mathrm{Fe}^{3+}$ ions in octahedral sites of $\mathrm{Co}-\mathrm{Fe}$ spinel oxides with enhanced oxygen catalytic activity for rechargeable zinc-air batteries. Angewandte Chemie International Edition, 2019, 58(38): 13291-13296

39. Hu M, Yao Z, Wang X. Graphene-based nanomaterials for catalysis. Industrial \& Engineering Chemistry Research, 2017, 56(13): $3477-$ 3502

40. Mohan V B, Lau K T, Hui D, Bhattacharyya D. Graphene-based materials and their composites: a review on production, applications and product limitations. Composites. Part B, Engineering, 2018, 142: 200-220

41. Qiu B, Xing M, Zhang J. Recent advances in three-dimensional graphene based materials for catalysis applications. Chemical Society Reviews, 2018, 47(6): 2165-2216

42. Gupta S, Joshi P, Narayan J. Electron mobility modulation in graphene oxide by controlling carbon melt lifetime. Carbon, 2020, 170: $327-337$

43. Georgakilas V, Tiwari J N, Kemp K C, Perman J A, Bourlinos A B, Kim K S, Zboril R. Noncovalent functionalization of graphene and graphene oxide for energy materials, biosensing, catalytic, and biomedical applications. Chemical Reviews, 2016, 116(9): 54645519

44. Xin L, Yang F, Rasouli S, Qiu Y, Li Z F, Uzunoglu A, Sun C J, Liu Y, Ferreira P, Li W, et al. Understanding Pt nanoparticle anchoring on graphene supports through surface functionalization. ACS Catalysis, 2016, 6(4): 2642-2653

45. Hummers W S Jr, Offeman R E. Preparation of graphitic oxide. Journal of the American Chemical Society, 1958, 80(6): 1339-1339

46. Qian J, Sun F, Qin L. Hydrothermal synthesis of zeolitic imidazolate framework-67 (ZIF-67) nanocrystals. Materials Letters, 2012, 82: 220-223

47. Chen B L, Ma G P, Zhu Y Q, Xia Y D. Metal-organic-frameworks derived cobalt embedded in various carbon structures as bifunctional electrocatalysts for oxygen reduction and evolution reactions. Scientific Reports, 2017, 7(1): 5266

48. Torad N L, Salunkhe R R, Li Y, Hamoudi H, Imura M, Sakka Y, $\mathrm{Hu} \mathrm{C}$ C, Yamauchi Y. Electric double-layer capacitors based on highly graphitized nanoporous carbons derived from ZIF-67. Chemistry (Weinheim an der Bergstrasse, Germany), 2014, 
20(26): 7895-7900

49. Lai L, Potts J R, Zhan D, Wang L, Poh C K, Tang C, Gong H, Shen Z, Lin J, Ruoff R S. Exploration of the active center structure of nitrogen-doped graphene-based catalysts for oxygen reduction reaction. Energy \& Environmental Science, 2012, 5(7): 7936-7942

50. Hou Y, Wen Z, Cui S, Ci S, Mao S, Chen J. An advanced nitrogendoped graphene/cobalt-embedded porous carbon polyhedron hybrid for efficient catalysis of oxygen reduction and water splitting. Advanced Functional Materials, 2015, 25(6): 872-882

51. Hussain M Z, van der Linden B, Yang Z X, Jia Q L, Chang H,
Fischer R A, Kapteijn F, Zhu Y Q, Xia Y D. Bimetal-organic framework derived multi-heterostructured $\mathrm{TiO}_{2} / \mathrm{Cu}_{x} \mathrm{O} / \mathrm{C}$ nanocomposites with superior photocatalytic $\mathrm{H}_{2}$ generation performance. Journal of Materials Chemistry. A, Materials for Energy and Sustainability, 2021, 9(7): 4103-4116

52. Hussain M Z, Yang Z X, van der Linden B, Huang Z, Jia Q L, Cerrato E, Fischer R A, Kapteijn F, Zhu Y Q, Xia Y D. Surface functionalized $\mathrm{N}-\mathrm{C}-\mathrm{TiO}_{2} / \mathrm{C}$ nanocomposites derived from metalorganic framework in water vapour for enhanced photocatalytic $\mathrm{H}_{2}$ generation. Journal of Energy Chemistry, 2021, 57: 485-495 